\title{
Escritos sobre cine en la revista Aisthesis: 1966-2016
}

\author{
Valeria de Los Ríos \\ Instituto de Estética, Facultad de Filosofía, Pontificia Universidad Católica de Chile. \\ edelo@uc.cl \\ Pablo Corro Pemjean \\ Instituto de Estética, Facultad de Filosofía, Pontificia Universidad Católica de Chile. \\ pablo.corro@gmail.com
}

En el presente artículo, llevaremos a cabo una revisión de los principales aportes de la revista Aisthesis al campo de los estudios cinematográficos. Aunque los artículos dedicados a la disciplina se diseminan a lo largo de la historia de la revista, pensamos que destacar algunos números paradigmáticos permitirá al lector interesado localizar más eficazmente estos aportes.

\section{Número 6}

“Cine”, artículo escrito por los profesores del Instituto de Estética, José Luis Villalba y Fidel Sepúlveda, y publicado en 1971 en la sección de Arte y Educación de Aisthesis 6 , representa el inicio de la escritura sobre cine en nuestra revista y un gesto extra de validación académica de los estudios de cine en la Pontificia Universidad Católica de Chile: el de la producción teórica.

En la década de 1940, en el seno de la Iglesia Católica, ya se había discutido con interés acerca del inquietante poder del cine para presentar modelos de comportamiento. Una reacción a esa influencia fue la conformación, durante la segunda mitad de los años cincuenta, de cine-clubes en muchos lugares de Europa, América Latina y Chile, gracias a la actividad educativa de los jesuitas. La doctrina de una interpretación humanista de los filmes y la identificación de películas inadecuadas para la conciencia de los cristianos relacionan la crítica de cine con cierta actitud pedagógica. En este contexto que pone en relación la estética, el arte y la educación, surge el artículo de Villalba y Sepúlveda, enmarcado además en un espacio académico de filiación ins- 
titucional católica. Los autores consideran la cualidad plástica del cine de articular existencialmente tiempo y espacio como prueba de su estatuto artístico, dejándola así por sobre otras cualidades cinematográficas, como la capacidad argumental, la iconocidad y la virtud mimética. Para hacer valer esta idea, recurren a la referencia tópica de lo educativo, en oposición con los criterios académicos ortodoxos.

En la época de publicación del artículo, el contexto editorial de la crítica y la teoría del cine en Chile era bastante precario; por ejemplo, la revista de cine Ecran, fundada en 1939, cuya continuidad se había basado en los géneros cinematográficos y en la atención textual y visual al star system -es decir, en los aspectos más difundidos y comerciales del cine- llevaba ya dos años sin publicarse.

Con la ilusión de representar el relevo editorial teórico de ese paradigma de magazine, casi al mismo tiempo que surge el interés por el cine en Aisthesis, aparecen la revista Primer Plano, de la Pontificia Universidad Católica de Valparaíso, de identificación crítica cahierista; y la Revista EAC, de la Escuela de Artes de la Comunicación de la Pontificia Universidad Católica de Chile, que atendía al cine en un contexto general semiológico y sociológico de estudio de medios. Ninguna de las dos publicaciones superó la decena de números; su existencia cultural e ideológica forma parte de los breves experimentos críticos que se permitieron nuestras universidades durante la Unidad Popular.

Un hito en la conciencia histórica sobre el cine chileno, surgido al mismo tiempo que aquel artículo fundacional de Villalba y Sepúlveda, es el libro Historia del Cine Chileno, del crítico Carlos Ossa Coo, editado en 1971 por Quimantú. Este relato secular y secuencial del cine chileno, que muchos teóricos actuales califican como incompleto o desprolijo en la definición del corpus, mientras que otros desaprueban debido al menosprecio casi generalizado que expresa por nuestros filmes, representa, pese a todo, el gesto atípico de interesarse por el cine chileno. Esta imputación sobre el descuido de lo local también concierne en esos años a la revista Aisthesis, y probablemente también a las filmografías de los cursos de cine del Instituto de Estética. Tuvieron que pasar treinta y tres años, hasta el 2004, para que en Aisthesis 37, "Estudios de Cine", se escribiera sobre cine chileno.

\section{Números 13, 17 y 21}

Pero no nos adelantemos. Luego de un silencio de diez años desde el texto de 1971, aparecen los artículos "Cine y Poesía" (Aisthesis 13, 1980-1981) y "Cine y Mito", de Luis Cecereu (Aisthesis 17, 1984). Ambos textos indagan en los fundamentos de la artisticidad del cine, desde perspectivas ontológicas y lingüísticas. La profundidad estética y filosófica de estos pensamientos sobre el medio expresivo revela que, por ahora, no son las obras -los filmes y sus contingencias- las que permiten legitimar el estatuto de arte del cine, sino sus condiciones y posibilidades antropológicas de existencia. 
En el número 21, de 1988, aparecen otros dos artículos sobre crítica de cine, muy distintos entre sí: "Problemas de Crítica de Cine", de Luis Cecereu, y "Crítica Simbólica de Cine”, de Gastón Soublette. El pensamiento sobre la organicidad del sentido en las obras, que resulta de la profundidad y coherencia de los materiales argumentales, dramáticos y retóricos del cine, es comprendido, en el primer caso, desde una perspectiva lingüístico-estructuralista, y, en el segundo artículo, desde un análisis psicoanalítico. Ambas referencias epistemológicas europeas revelan que, al menos en lo que se refiere al pensamiento cinematográfico, Aisthesis presenta una clara dependencia cultural al canon de occidente, la que ya veremos si ha sido superada.

En otro sentido, podemos entender el pensamiento del cine que vamos reseñando, articulado en función del mito, la poesía y la crítica, como el movimiento inicial de una práctica de reflexión científica sobre un arte en legitimación, pero también como una zona teórica inocua, en la que se obvia la historia proscrita, en suspenso, o antagonista, del cine chileno durante la dictadura.

\section{Número 23}

Como reacción a la indiferencia crítica de Aisthesis hacia el cine chileno y hacia las relaciones entre cine y política, en el número 23 de la revista, aparece el artículo "El cine chileno en los laberintos del subdesarrollo", del profesor Luis Cecereu Lagos. Aquí, Cecereu emprende la tarea de relatar, bajo el signo de la precariedad material y de la indiferencia espectatorial, la aventura del cine chileno, de ficción y no ficción, desde la década del treinta hasta los filmes contemporáneos al momento de la escritura: $L a$ luna en el espejo, de Caiozzi (1990), e Imagen Latente, de Perelman (1990). Esta amplia radiografía considera los roles dramáticos de los espectadores en el devenir secular del cine chileno; el contexto político gubernamental; las condiciones productivas locales; y el papel de los cineastas, quienes son tratados como autores. En función de la perspectiva estética autónoma que implica esta categoría, es que Cecereu rescata algunas obras del cine semi-industrial de José Bohr, además de los trabajos de Di Lauro y Yankovic, Sergio Bravo, Caiozzi y, especialmente, Raúl Ruiz. Por otro lado, teniendo en cuenta el fenómenos del "Nuevo Cine Chileno", enmarcado en el contexto del "Nuevo Cine Latinoamericano", Cecereu comprende lo político no como mera característica condicionante de los filmes, sino como el objetivo de estos: el mérito político de las obras cinematográficas contemporáneas, críticas de la historia reciente, es también la organicidad audiovisual de su estética. Un último aspecto que da cuenta del cambio de actitud hacia el cine chileno que evidencia este artículo es que en más de un párrafo se sugiere que la gran originalidad de la producción nacional, pese a la invariante de la pobreza, se encuentra en su cine documental, el que por lo demás aún no había sido atendido por Aisthesis. 


\section{Número 37}

La plenitud epistemológica del cine en Aisthesis se expresa en el número 37, del año 2004. Esta edición se dedicó íntegramente al estudio del fenómeno cinematográfico a través de las secciones de Estudios, Entrevistas y Reseñas. Pese a que el número contempla teorizaciones generales sobre el lenguaje y los formatos del cine, como es el caso del artículo de José Román, "Espacio y tiempo en el cine moderno", que piensa en las contribuciones estructurales del montaje, el plano secuencia y el fuera de campo al cine moderno; o el de Miguel Vidaurre, quien, en "Apología de la fragmentación", se refiere a la posibilidad estética e ideológica del formato de cortometraje, la mayoría de los artículos que aparecerán tanto en este número como en los sucesivos estarán centrados en el cine chileno. Al respecto, el artículo "La aventura y la patria: El Húsar de la Muerte de Pedro Sienna”, de Jorge Ruffinelli, junto al de Pablo Corro, “Tramposos", cubren críticamente los extremos cronológicos del cine local, atendiendo, en el primer caso, a los méritos estéticos de aquel éxito de taquilla de 1925; $y$, en el segundo, considerando las relaciones entre diversos filmes latinoamericanos de comienzos del 2000, referidos en clave policial al lucro como móvil en la gran escala de lo institucional y en la pequeña de lo intersubjetivo. Conviene señalar que en este número reaparece la reflexión hermética del cine del profesor Soublette, en el artículo "La Cara Oculta del Cine". Este análisis, dedicado a un corpus de filmes recientes, dialoga con su otro artículo de 1988, y permite considerar, desde el ámbito complementario de la escritura, que esta doctrina de crítica simbólica constituye un elemento de singularidad y continuidad ideológica en las comprensiones del cine que profesa el Instituto de Estética.

Atención especial, en este breve espacio, creemos que merecen los números 47 y 48, de 2010. Ambos expresan la prioridad del pensamiento político del cine, primero en Chile y luego en Latinoamérica, y si bien las justificaciones para ese enfoque provienen de los diversos espacios dramáticos pendientes de la teoría local, la contingencia del bicentenario de la República de Chile y de otras naciones hermanas, determina histórica y, en gran medida, trágicamente, los análisis que en ellos se reúnen.

\section{Número 47}

En el año 2010, la revista Aisthesis dedicó su dossier al tema del cine y la política en Chile. El volumen está conformado por diez artículos que revisan distintas etapas y producciones nacionales, en las que se exploran modulaciones posibles del vínculo entre cine y política. En el primer artículo, Antonella Estévez propone que largometrajes de la primera década del siglo xxi, como Play, La Sagrada Familia, Y las vacas vuelan, En la cama o El cielo, la tierra y la lluvia, desafían los estándares de la representación naturalista, poniendo en el centro de su narración la reflexión respecto al lenguaje 
cinematográfico. Los realizadores de estos filmes comparten un entrenamiento formal en lo cinematográfico, además de una amplia cultura audiovisual. También tienen en común haber nacido durante la dictadura militar en Chile y haber comenzado su trabajo profesional durante la transición democrática, de modo que ese contexto político, social y cultural deviene en melancolía cinematográfica, lo que se caracteriza a través de un uso particular de las posibilidades del lenguaje fílmico.

En "Hacia una política en tránsito. Ficción en el cine chileno (2008-2010)", Carolina Urrutia propone que el cine moderno trasladó los conflictos políticos y sociales a terrenos más domésticos e íntimos. Películas como Huacho, de Alejandro Fernández; Tony Manero, de Pablo Larraín; Turistas, de Alicia Scherson; o El Pejesapo, de José Luis Sepúlveda, proponen una reflexión sobre un inestable "estar en el mundo", actitud que se hace manifiesta a través de ciertas operaciones formales y estéticas que insisten en esa sensación de incertidumbre y de renuncia a la comprensión del sujeto al momento de establecer una percepción sobre su futuro. En "Estrategias para (no) olvidar: notas sobre dos documentales chilenos de la post-dictadura", Elizabeth Ramírez revisa una serie de documentales autobiográficos que han dado cuenta de las transformaciones experimentadas por la sociedad chilena en los últimos cuarenta años: la ilusión del proyecto socialista, su posterior derrumbe y, finalmente, la arremetida del sistema neoliberal. En un artículo en coautoría, Juan Pablo Silva y Valentina Raurich afirman que el nuevo cine chileno construye una particular versión de lo popular, configurándolo como un estilo de vida y como clase social que se encuentra en tensión continua con la clase dominante.

En "Sergio Bravo y tendencias del montaje", Pablo Corro propone que desde 1957, con películas como Las Callampas, de Rafael Sánchez, y Mimbre, de Sergio Bravo, el cine chileno se ha identificado retóricamente con el montaje, puesto que a través de él no solo se expresa la inusitada y conflictiva multiplicación de las posibilidades de organización teórica y práctica de la vida individual y colectiva, sino que además se manifiesta el cambio como un valor y el sistema como el principio estructural de todo. En “¿Espectador en acción?: representación e identificación del pueblo/masa en El Chacal de Nahueltoro", Catalina Donoso observa cómo esta película representa al espectador implícito y de qué manera apela a él. A través de su estudio, Donoso concluye que El Chacal de Nahueltoro ejemplifica el problema de cómo conciliar el adoctrinamiento de las masas con su autonomía, producto de lo cual se produce un residuo marginal que permanece siempre en los bordes, sin integrarse más que como mito o como la mediatización de su propio discurso.

En "Raúl Ruiz a través del Espejo: de la representación a la alegoría", Valeria de los Ríos afirma que en películas como Qué hacer, Palomita blanca, Colloque des chiens y L'Hypotése du tablean volé, Raúl Ruiz juega con diferentes niveles de representación, en los que nunca hay un intento de reproducir la realidad de forma mimética. Aun más, en sus filmes franceses, Ruiz utiliza las convenciones cinematográficas del realismo para producir un efecto irreal. Estas películas muestran y hablan sobre la experiencia 
de estar afuera, de la alienación y dislocación, lo que para Ruiz es una alegoría de la condición latinoamericana. En su artículo en colaboración, Luis Horta e Iván Pinto analizan las películas Realismo socialista, de Raúl Ruiz, y Queridos compañeros, de Pablo de la Barra, para afirmar que Realismo socialista excede y agota el discurso ficcional clásico y el discurso militante cerrado, mientras que Queridos compañeros propone la interrupción como marca traumática del suceso político en el discurso y el dispositivo del filme.

En “La política de una ausencia”, José Santa Cruz intenta pensar la relación entre lo político y el arte como una figura ausente en el cine chileno actual, proponiendo una lectura desde la noción de "estéticas de la emergencia", acuñada por Reinaldo Laddaga. Para finalizar este número, Catalina Larraín propone que la aparición de nuevas tecnologías digitales en la producción cinematográfica chilena ha modificado los costos y procesos implicados en la cadena de producción y exhibición, además de posibilitar el surgimiento de nuevas temáticas y estilos.

\section{Número 48}

El número 48 de la revista está dedicado a las relaciones entre cine y política en Latinoamérica. Está formado por ocho artículos de temáticas diversas, cuyo eje central es la producción cinematográfica latinoamericana. El dossier está encabezado por el texto del documentalista y académico José Román, quien analiza la relación cine y política en torno a los festivales de cine latinoamericano celebrados en Viña del Mar en 1967 y 1969, en los que el "nuevo cine" intentaba representar la realidad social y política de los países del continente, a través de temas como la inequidad social, la dependencia cultural, los regímenes dictatoriales y la violencia política.

En "Raúl Ruiz: Ontología de lo Fantástico. Territorios, Políticas Estéticas y Polisemia Visual", Adolfo Rocca-Vásquez presenta el cine de Ruiz como un cine de paradojas, relatos laberínticos y recursivos, que dan forma a una poética lúdica y contradictoria, configurada como un cine de desacuerdo y resistencia frente a los cánones narrativos tradicionales. En otro artículo, Juan Carlos Arias se pregunta por la frontera entre documental y ficción en la producción documental contemporánea a partir de dos ejes: la ontología y el lenguaje. A grandes rasgos, Arias propone que en el documental, lo real no se registra ni se representa, sino que "aparece" a través del montaje, como una especie de visión. En "Archivo, Cine, Política: Imágenes Latentes, Restos y Espectros en Films Argentinos y Chilenos", Wolfgang Bongers postula -siguiendo a Wolfgang Ernst- que el archivo es una "matriz prefigurada de la realidad registrada", la cual, en el caso de las producciones latinoamericanas, debe ser contrastada con las experiencias de violencia, tortura e injusticia sufridas por pueblos, comunidades e individuos. 
Mónica Villarroel analiza el cine de exploradores en la época silente como una construcción eurocéntrica que reproduce las relaciones coloniales de poder, las cuales, por un lado, enfatizan la modernidad y el progreso y, por otro, el exotismo, la minusvalía y la precariedad de las culturas indígenas locales. Para comprobar esta hipótesis, Villarroel analiza el filme Tierras Magallánica, de Alberto de Agostini. En "Melodramas, Identidades y Modernidades Latinoamericanas en el Cine Actual: de Amores Perros a Sábado", Claudio Salinas propone que lo melodramático hace ingresar narrativamente a nuestras sociedades en la modernidad periférica. El argentino Esteban Diapola analiza, en "Las Formas Políticas del Cine Argentino: Montajes, Disrupciones y Estéticas de una Tradición", las formas políticas del cine argentino desde los años sesenta a la actualidad, y propone hablar de "formas políticas" en lugar de "cine político". Además, distingue tres períodos de producción: los años sesenta y setenta como la irrupción de la política en el cine; los años ochenta como el desplazamiento de la política por la denuncia moral; y los años noventa y post 2001 como un retorno de lo sensible o como el advenimiento de las "políticas de lo sensible". En “Tránsito. Desplazamientos Nimios en el Cine Latinoamericano (2000-2010)", Luis Valenzuela define, a partir de algunas reflexiones de Marc Augé, Isaac Joseph y Michel de Certeau, las posibilidades de tránsito como un "andar que enuncia" los desplazamientos nimios de sujetos omitidos por discursos hegemónicos, lo que se puede ver en películas como Play, Historias mínimas, Familia rodante, Paraíso travel, Un hombre aparte, Nema problema, ¿Quién mató a la llamita blanca?, Machuca, Y tu mamá también y La teta asustada, entre otras.

\section{Número 58}

Al final de esta reseña destacamos el número 58, de diciembre de 2015, que incluye el dossier "Pier Paolo Pasolini y las artes: vigencia estética y política". Los textos que contiene se refieren al estatuto político de la estética cinematográfica, dramatúrgica, literaria y lírica de la obra de Pasolini, en la que la política se concibe como disciplina crítica de carácter poético que, en algunos de los abordajes, se relacionó con la obra literaria de artistas chilenos. Este dossier y el coloquio precedente de 2014 fueron concebidos por el Instituto de Estética para conmemorar los cincuenta años del asesinato del artista.

Una determinación académica reciente, que tiene relación con el espacio teórico sobre cine que representa la revista Aisthesis, es la creación del magíster en Estudios de Cine. La primera versión se iniciará en abril de 2017 y reunirá a un sólido equipo de académicos, cuyas obras, además de integrar los índices que considera esta reseña, animan la actividad crítica del medio, a través tanto de libros como de investigaciones científicas. Creemos que, al margen de sus esquemas de selección editorial, la relación entre la revista y el magíster será una relación virtuosa, crítica y dialogal. 